\title{
Vascular Stiffness and Increased Pulse Pressure in the Aging Cardiovascular System
}

\author{
Jochen Steppan, Viachaslau Barodka, Dan E. Berkowitz, and Daniel Nyhan \\ Department of Anesthesiology and Critical Care Medicine, Johns Hopkins Medical Institutions, Baltimore, MD 21287, USA \\ Correspondence should be addressed to Daniel Nyhan, dnyhan1@jhmi.edu
}

Received 21 January 2011; Revised 24 March 2011; Accepted 8 June 2011

Academic Editor: Arshed A. Quyyumi

Copyright ( $) 2011$ Jochen Steppan et al. This is an open access article distributed under the Creative Commons Attribution License, which permits unrestricted use, distribution, and reproduction in any medium, provided the original work is properly cited.

Aging leads to a multitude of changes in the cardiovascular system, including systolic hypertension, increased central vascular stiffness, and increased pulse pressure. In this paper we will review the effects of age-associated increased vascular stiffness on systolic blood pressure, pulse pressure, augmentation index, and cardiac workload. Additionally we will describe pulse wave velocity as a method to measure vascular stiffness and review the impact of increased vascular stiffness as an index of vascular health and as a predictor of adverse cardiovascular outcomes. Furthermore, we will discuss the underlying mechanisms and how these may be modified in order to change the outcomes. A thorough understanding of these concepts is of paramount importance and has therapeutic implications for the increasingly elderly population.

\section{Hallmarks of the Aging Cardiovascular System}

Aging leads to a multitude of changes in the cardiovascular system including increased vascular stiffness. In fact, agerelated increases in blood pressure are mainly attributable to an increase in systolic blood pressure while maintaining or having a slight decrease in a diastolic blood pressure. This leads to a widening in pulse pressure (difference between systolic and diastolic blood pressure) [1]. Systolic hypertension is so closely related to aging that people 65 years of age have a $90 \%$ chance of developing hypertension in their lifetime [1]. Isolated systolic hypertension is the most common subtype of hypertension in the middle-aged and elderly and is tightly coupled to increased arterial stiffness and pressure augmentation by reflected waves. Other causes of a widened pulse pressure, including severe anemia, aortic insufficiency, thyrotoxicosis or arteriovenous shunting, are much more uncommon.

The arterial system has two major functions. Firstly, it acts as a conduit to deliver oxygenated blood and nutrients to the organs. Secondly, it provides a cushion to soften the pulsations generated by the heart such that capillary blood flow is almost continuous. The human body is highly adapted to achieve those functions. The composition of the arteries, especially the media, changes significantly as one moves from proximal (central large arteries, e.g., aorta and its major branches) to distal (peripheral, predominantly muscular arteries, e.g., brachial or radial). While the predominant fibrous elements in the thoracic aorta contain mainly elastin, the more distal arteries contain mainly collagen. This difference is vital for the central vessels to maintain their Windkessel function of cushioning pulsatile blood flow. With aging disruption of the cross-linking of elastin molecules leads to weakening of the elastin array with predisposition to mineralization by calcium and phosphorous, all of which lead to increased arterial stiffness $[2,3]$. The widening pulse pressure seen with aging is a direct surrogate of arterial stiffness. The increase in vascular stiffness has direct implications for ventricular-arterial coupling (interaction of the heart with the systemic vasculature) [4]. The increase in systolic blood pressure increases the systolic workload of the left ventricle and increases left ventricular end-systolic stiffness and reduces diastolic compliance [4]. This leads to increased oxygen consumption, left ventricular hypertrophy, and potentially subendocardial ischemia due to imbalance in myocardial oxygen supply and demand. 


\section{Vascular Stiffness: Mechanisms}

The normal young vascular tree, particularly the aorta, has the ability to cushion the pulsatile ventricular ejection and to transform it into almost continuous flow [5]. This phenomenon is often described as the Windkessel function and requires a high degree of aortic compliance [6], defined as a change in volume in response to a change in pressure $(C=\Delta V / \Delta P)$. Vascular stiffness or elasticity is the reciprocal of compliance. This needs to be distinguished from (i) resistance which characterizes the relationship between mean pressure and flow and (ii) impedance which is a measure of how much a structure resists motion when subjected to a given force. In oscillating systems, instantaneous measurements are also influenced by those that immediately precede them.

The elasticity of a given arterial segment is not constant but rather depends on its distending pressure [7]. A higher distending pressure leads to an increase in recruitment of collagen fibers and therefore a reduction in elasticity [8]. This distending pressure is determined by the mean arterial pressure and must be considered whenever measurements of arterial stiffness are made. In addition to elastin, arterial wall smooth muscle bulk and tone influence arterial stiffness. Thus, the endothelium because of its capacity to modulate smooth muscle tone modulates stiffness. Moreover, vessel diameter also influences the stiffness of vessels. In general smaller vessels are relatively stiffer than bigger vessels because of their smaller radius [9]. A large vessel can accept a larger volume for the same change in distending pressure and thus has a greater compliance. Furthermore, wall composition varies with size, with the media of large central vessels' composed mainly from elastin, while peripheral conduit arteries contain relatively more collagen. With aging, this structure of the arterial wall changes as a consequence of fractures of the elastic lamina, loss of muscle attachments, increase in collagen fibers, local inflammation, infiltration of vascular smooth muscle cells and macrophages, fibrosis, deposition of mucoid material, focal media smooth muscle cell necrosis, and calcification. The intima-medial thickness triples between the ages 20 and $90[10,11]$. A major component of this compositional change with aging is a consequence of elastin fracture, with elastin being progressively replaced by collagen [12]. This results in major age-related changes in the vasculature: it increases arterial stiffness leading to increases in systolic blood pressure and a widening pulse pressure. Furthermore these changes result in arterial dilatation as weight bearing elastin breaks down $[2,3]$.

Stiffness is also increased by the accrual of advanced glycation end (AGE) products [14]. These result from irreversible nonenzymatic glycation of proteins (e.g., collagen) [15]. Cross-linking and AGEs formation can also involve elastin, degrading the elastic matrix of the vessel wall [16]. Furthermore AGE increases the formation of oxygen radicals, proinflammatory cytokines, growth factors, and vascular adhesion molecules [17]. Those mediators increase vascular stiffness via matrix metalloproteinase, increasing smooth muscle tone, attenuating vasodilation, and promoting atherosclerotic plaques [18-21]. In a recent clinical trial by Kass et al., the nonenzymatic breaker of advanced glycation end-product crosslinks ALT-711, has been shown to improve total arterial compliance in aged humans with vascular stiffness, and may therefore provide a novel therapeutic approach for this abnormality [22].

In addition to the aforementioned changes, vascular smooth muscle tone and endothelial signaling exert a significant effect on vascular stiffness [17]. Mechano-stimulation can directly alter vascular tone by cell stretch, changes in calcium signaling, oxidative stress, and nitric oxide production [24-26]. The major mediator of endotheliumdependent vasorelaxation is nitric oxide (NO) [27]. It is derived from L-arginine by NOS (nitric oxide synthetase) [28]. NOS uncoupling, the generation of reactive oxygen species instead of NO [29], contributes to age-related endothelial dysfunction [30], increased vascular stiffness, slower ventricular relaxation [31], and atherosclerosis [32], all of which increase PWV. NOS uncoupling can have several etiologies including limited substrate (arginine) or cofactor (Tetrahydrobiopterin) availability, as well as a recently identified posttranslational modification by the enzyme glutathionylation (oxidized glutathione) [33-35]. In addition to its vasoactive effects, NO modulates the activity of the matrix crosslinking enzyme transglutaminase (TG) via S-nitrosylation, also leading to increases in arterial stiffening $[36,37]$. Other mechanisms recognized as contributing to the development of increased vascular stiffness in aging include a decrease in NOS expression [38], an increase in xanthine oxidase activity $[39,40]$, and an increase in reactive oxygen species $[39,41]$, while stiffening itself can lead to a decrease in NOS activity [42].

\section{Measurements of Vascular Stiffness}

The arterial pressure waveform is a composite of two waveforms, namely, a forward pressure wave due to ventricular contraction and ejection of blood into the aorta and a backward wave created by reflections at vascular branching points and at points of impedance mismatch (branch points, abrupt change in vessel diameter, and high resistance arterioles; Figure 1) [23]. The speed of travel of this wave along the artery is called pulse wave velocity (PWV) [13]. In young vascular beds, the reflected wave arrives back at the aortic root during diastole [12]. Increased arterial stiffness, as that occuring for example with aging, results in an increase in PWV and the reflected wave arrives back to the central circulation during systolic ejection. This adds to the forward wave, augmenting systolic blood pressure and widening pulse pressure. This amplification can be quantified by measuring the augmentation index utilizing applanation tonometry. The augmented component is represented by the difference between the first and second systolic peaks, and the augmentation index is defined as the ratio of this component to pulse pressure (Figure 2). Therefore the augmentation index represents a complex measure of wave reflection and incorporates arterial stiffness but is not in itself a measure of stiffness [43]. Another index of vascular stiffness 


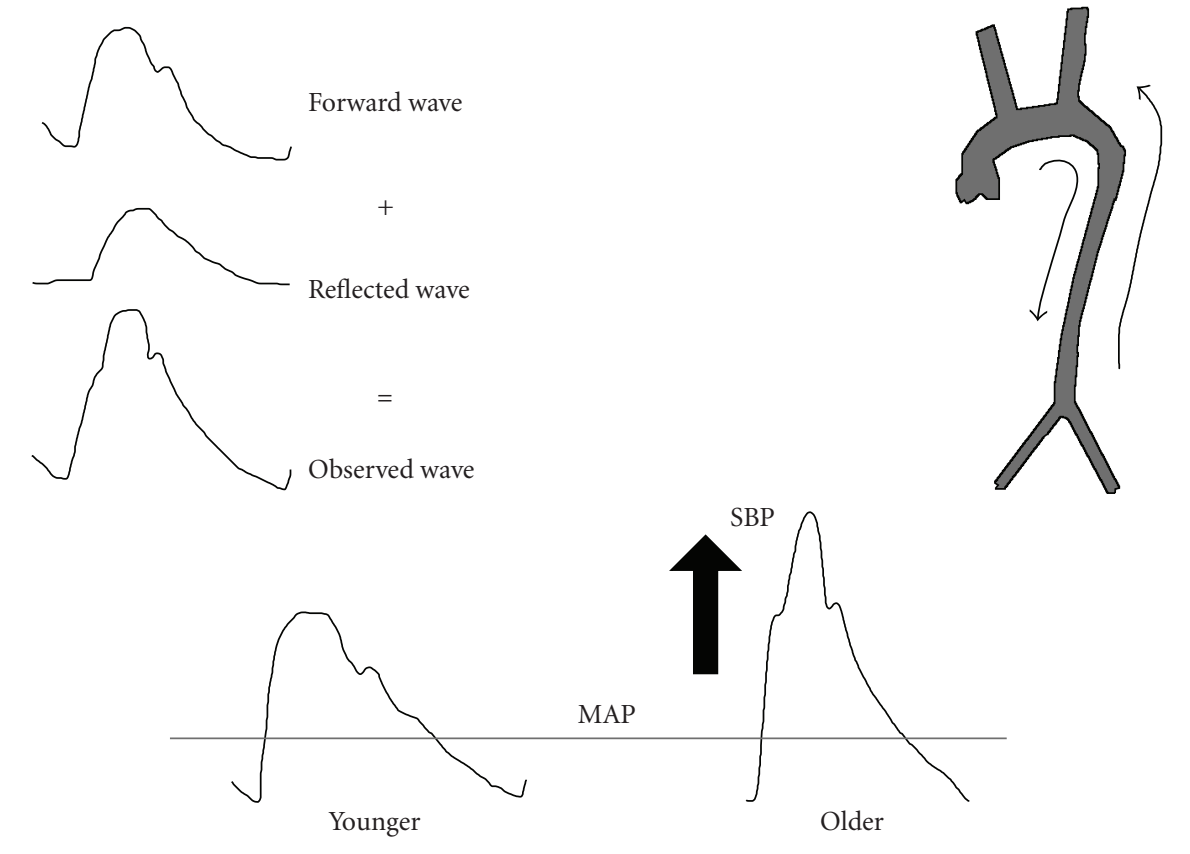

FIGURE 1: This figures illustrates the composition of the arterial pressure waveform from a combination of a forward pressure wave created by ventricular contraction and a reflected wave. MAP: mean arterial pressure; SBP: systolic blood pressure (see [13]).

is pulse pressure amplification, which can be quantified as the ratio of the amplitude of proximal pulse pressure and distal pulse pressure [44]. Of note, there is recent evidence by Mitchell et al. that questions the dominant role of the reflected pressure wave. They studied an unselected community-based population and suggested that the latelife increases in pulse pressure are attributable predominantly to an increase in forward pressure wave amplitude and that wave reflection plays only a minimal role [45]. Irrespective of which factor contributes the most, aging is associated with systolic hypertension, increased pulse pressure, and increased ventricular loading conditions. Augmentation index, pulse pressure amplification, and especially PWV are increasingly utilized as a marker of cardiovascular disease [46]. PWV increases with stiffness and is defined by the MoensKorteweg equation: $\mathrm{PWV}=\sqrt{ }(E h / 2 p R)$, where $E$ is Young's modulus of the arterial wall, $h$ is wall thickness, $R$ is arterial radius, and $p$ is blood density. Despite this rather complex formula, measurement of PWV is relatively simple. The arterial pulse wave is recorded at both proximal artery site (e.g., common carotid) and distal artery site (e.g., femoral or brachial) [47]. The time delay between the arrival of the pulse wave is obtained either by simultaneous measurement or by gating to the peak of the R-wave of the ECG. The distance is measured over the body surface and the PWV is calculated as distance/time $(\mathrm{m} / \mathrm{s})$. The measurement of distance between the two points is only an estimate of the true distance given the individual body habitus. Arterial pulse wave can be detected by pressure sensitive transducers, Doppler ultrasound, or applanation tonometry. Another noninvasive but more complex option is to measure PWV by MRI. This has the advantage of determining the exact path of the pressure wave but is time consuming, impractical clinically, and very costly.

Central vascular stiffness can be assessed noninvasively by measuring pulse wave velocity, assessing pressure waveforms, or measuring pulse pressure. Caution must be exercised when utilizing pulse pressure as an index of central stiffness. In peripheral arteries, reflection sites are closer, and this results in a greater amplification of the pressure wave in peripheral arteries. Hence in young individuals with healthy vessel properties, peripheral pulse pressure is normally greater. In elderly individuals, including patients with hypertension or diabetes, central pulse pressure increases because of altered stiffness properties, and central pulse pressure can approach and indeed equal peripheral pulse pressure.

\section{Vascular Stiffness Measurements as a Prognostic Indicator}

Many large epidemiologic studies, including one of the Framingham cohorts including 2,232 patients, established the role of systolic blood pressure and pulse wave velocity as a predictor for adverse cardiovascular events [48, 49]. Additional studies have demonstrated that brachial pulse pressure is a strong and independent predictor for congestive heart failure and stroke in hypertensive patients and in the general population [50-54]. In the ABC study with 2,488 elderly participants, higher PWV was associated with higher cardiovascular mortality, congestive heart failure, and stroke after adjustment for age, gender, race, systolic blood pressure, known cardiovascular disease, and other recognized cardiovascular risk factors [55]. Similar results were obtained in the 
Brachial artery

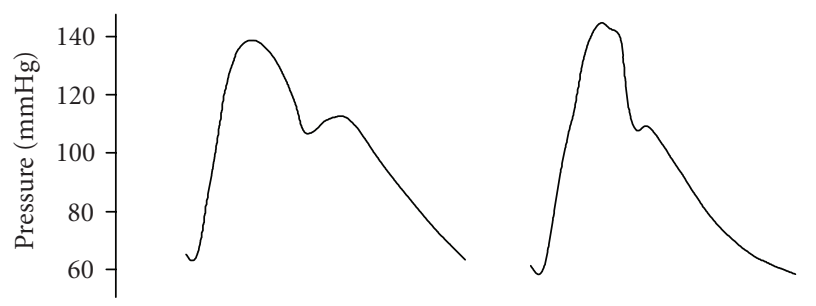

(a)

Central aorta
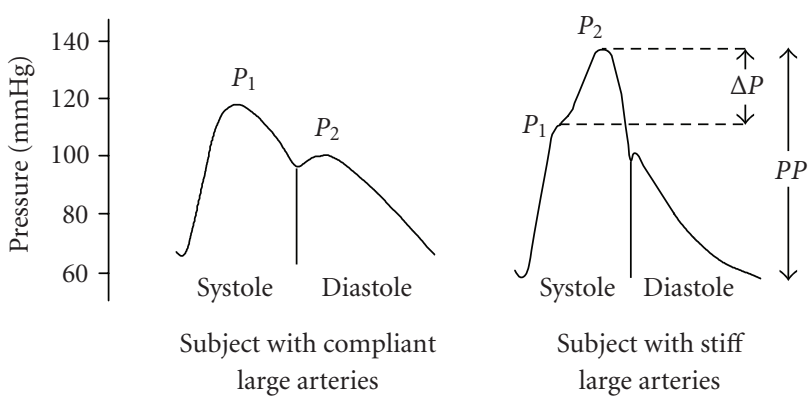

(b)

FIGURE 2: Schematic representation of pulse pressure amplification. Pressure tracings from the brachial artery and central aorta are shown, from a young individual with a highly compliant vasculature tree (left) and from an old one with stiff vessels (right). Despite similar brachial blood pressures, central blood pressures vary considerably. In young individuals, $P_{1}$ (which coincides with systolic blood pressures) marks the outward traveling blood pressure wave, while $P_{2}$ represents the arrival of the reflected pressure wave in diastole, augmenting diastolic blood pressure, and coronary filling. Pulse pressure augmentation in old, stiff vessels leads to a significant increase in $P_{2}$ as compared to $P_{1}$, as wave reflection occurs earlier and faster, leading to an augmentation in systolic blood pressure. Augmentation index is calculated as the difference between the second $\left(P_{2}\right)$ and first $\left(P_{1}\right)$ systolic peaks (delta $P$ ) as a percentage of pulse pressure (see [23]).

Rotterdam study that included 2,835 healthy subjects, which showed that aortic pulse wave velocity is an independent predictor of coronary artery disease and stroke [56]. The Monica study with 1,678 participants aged $40-70$ and a 10year followup demonstrated that increased aortic pulse wave velocity predicted a composite of cardiovascular outcomes [57]. This was recently replicated by Wang et al. studying 1,980 outpatients (mean age $50 \pm 13$ years) with a 10 -year followup, showing that PWV was significantly associated with all-cause and cardiovascular mortality, independent of previous cardiovascular disease [48]. Similar results were obtained in the Strong Heart Study of 3,520 individuals, which showed that noninvasively determined central pulse pressure is a better predictor of vascular hypertrophy, atherosclerosis, and cardiovascular events than brachial blood pressure [58]. The ASCOT study of 259 participants corroborated these findings [59], as well as a study by Safar et al. on 180 patients which demonstrated that pulse pressure amplification is an independent predictor of allcause mortality [60]. Finally, and of critical importance, the Dublin Outcome Study of 11,291 individuals which included middle-aged participants without hypertension clearly demonstrated that an arterial stiffness index and pulse pressure were independent predictors of cardiac mortality and stroke [61]. This was again reinforced by an even larger study in Paris, involving 125,151 middle-aged patients over 12 years without cardiovascular disease undergoing a regular health checkup [62]. The authors showed that brachial pulse pressure, calculated carotid pulse pressure, and carotid-brachial pulse pressure amplification all predict cardiovascular mortality, with carotid-brachial pulse pressure amplification being the strongest predictor [62].

In addition to being a predictor of cardiovascular events in the general population, pulse pressure has also been shown to be independently and significantly associated with renal dysfunction and renal failure after coronary artery bypass graft surgery [63]. In this international prospective multicenter clinical trial involving 4801 patients, every $20 \mathrm{mmHg}$ increase in perioperative pulse pressure above $40 \mathrm{mmHg}$ was associated with significant increase in the rate of renal dysfunction or renal failure [63]. Furthermore, elevated pulse pressure has been shown to be a predictor of stroke after cardiac surgery [64]. More recently pulse pressure has also been shown to be an independent predictor of cardiovascular deaths in a similar cohort after coronary artery bypass graft surgery [65].

A recent systematic review and meta-analysis by Vlachopoulos et al. evaluated 17 longitudinal studies that studied the effects of aortic PWV on a total of 15,877 patients for an average of almost 8 years [46]. They showed that the pooled relative risks increase in a stepwise fashion from the first to the third tertile. Furthermore they divided their analyses into three categories: (a) high versus low aortic PWV, (b) increase in aortic PWV by $1 \mathrm{~m} / \mathrm{s}$, and (c) increase in aortic PWV by 1 standard deviation, all of which show that in high-risk (subjects with coronary artery disease, renal disease, hypertension or diabetes) and low-risk subjects (general population) there is an increase in total cardiovascular events, cardiovascular mortality, and all-cause mortality [46] (Figure 3). They therefore conclude that PWV is a very strong predictor of cardiovascular events and allcause mortality and supported the implementation of aortic pulse wave velocity into clinical practice [46]. This study was followed by an initiative to determine and establish reference values for pulse wave velocity in healthy subjects that can now be used to identify people at higher risk in a certain age group [66].

\section{Vascular Stiffness and Treatment/Management Strategies}

Central pulse pressure is a strong predictor of adverse cardiovascular outcomes. The CAFE study which involved 2,199 patients in five centers evaluated two different blood pressure regiments [67]. A combination of amlodipine and an ACE inhibitor was superior in lowering central pressures compared to a combination of atenolol and a thiazide diuretic 
Aortic PWV (high versus low)

Studies $\mathrm{RR} \quad 95 \% \mathrm{Cl} \quad \mathrm{RR}(95 \% \mathrm{Cl})$ $(N)$

Total cardiovascular events

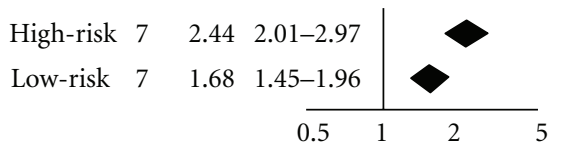

$Q=8.7, P=0.003$

Cardiovascular mortality

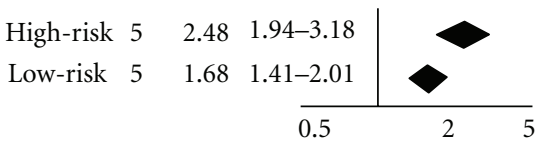

$Q=6.2, P=0.013$

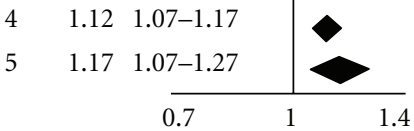

$Q=0.7, P=0.4$

(b)

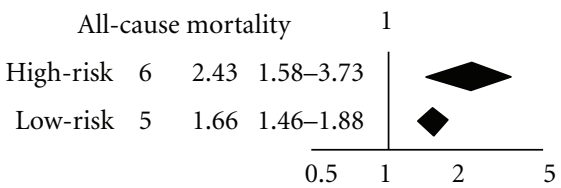

$Q=2.75, P=0.098$

Aortic PWV (per 1 m/s increase)

Studies $\quad \mathrm{RR} \quad 95 \% \mathrm{Cl} \quad \mathrm{RR}(95 \% \mathrm{Cl})$ $(N)$

$Q=0.45, P=0.5$

(a)

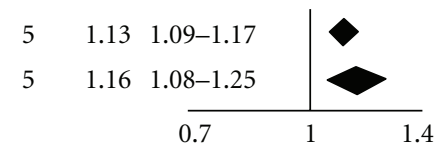

$4 \quad 1.42 \quad 1.24-1.64$

$5 \quad 1.5 \quad 1.24-1.81$

0.7

$Q=0.18, P=0.68$

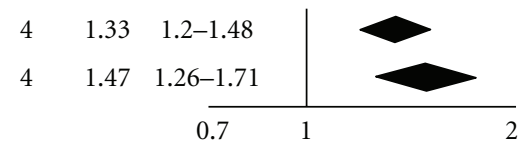

$Q=1.04, P=0.31$
Aortic PWV (per 1 SD increase)

Studies $\quad \mathrm{RR} \quad 95 \% \mathrm{Cl} \quad \mathrm{RR}(95 \% \mathrm{Cl})$

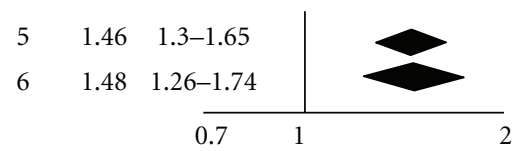

$Q=0.01, P=0.92$

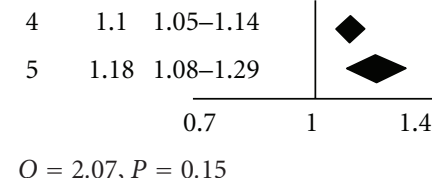

(c)

FIgure 3: This figure shows pooled RR and 95\% CI for aortic PWV and total CV events (a), CV mortality (b), and total mortality (c), according to baseline risk and disease state. Data are provided for high versus low aortic pulse wave velocity (PWV) (left column), increase in aortic PWV by $1 \mathrm{~m} / \mathrm{s}$ (middle column), and increase in aortic PWV by $1 \mathrm{SD}$ (right column) (see [46]).

[67]. This was true despite the fact that both medical regiments lowered brachial blood pressures to the same extent. Moreover, long-term cardiovascular outcomes were superior in the group treated with a combination of amlodipine plus an ACE inhibitor. The authors suggested that differences in central aortic pressures may be a potential mechanism underlying the different clinical outcomes between different blood pressure treatments. Subsequent analyses showed that the main reason underlying the apparent lack of effect of beta-blockers plus a diuretic on central pressures was that beta-blockers lowered heart rate to a greater degree than amlodipine plus ACE inhibitors. This leads to a higher augmentation index and therefore higher central aortic pressures. The reasons for this are twofold: (i) a reduction in heart rate leads to an increase in stroke volume to maintain cardiac output, which when ejected into a stiff aorta causes an increase in systolic blood pressure, (ii) a lower heart rate prolongs the cardiac cycle duration, which delays the time to peak of the outgoing pulse wave and causes the reflected wave to return in late systole, resulting also in an increase in systolic blood pressure. After these investigators adjusted for heart rate, the differences in central systolic and pulse pressures between treatment arms were no longer significant and the differences in indices of central blood pressure augmentation were minimal.

Research in the area of vascular stiffness is motivated by the desire to understand and interrogate underlying mechanisms and thus to modulate stiffness and the resultant cardiovascular sequelae. Many interventions involving lifestyle and dietary modifications, for example, smoking cessation [68], use of unsaturated fatty acids [69], isoflavones (abundant in soy beans) [70], reduced dietary salt intake [71], regular cardiovascular exercise [72], and moderate alcohol consumption [73, 74] have all been linked to reducing vascular stiffness. Other strategies involve pharmacologic interventions like calcium channel blocker, diuretics, ACE inhibitors, beta-blockers, nitrates, phosphodiesterase5 inhibitors, and statins. Even though all these therapies lower blood pressure, their effect on arterial stiffness is only modest. A substudy of the REASON trial by de Luca et al. on 146 subjects showed that a combination of ACE inhibitor and a nonthiazide sulphonamide lowered left ventricular mass, as well as central and brachial blood pressure to a greater extend than atenolol therapy [75]. Similar results were seen in a study by Morgan et al. on 32 elderly patients; they showed that augmentation pressures on beta-blockers was greater than with placebo, while augmentation pressures following ACE inhibitors, calcium channel blockers, or diuretics were significantly less compared to placebo [76]. The lowest central aortic pressures were achieved with calcium-blocking drugs and diuretics [76]. In a small study by Hayashi et al., on 24 normotensive elderly subjects, administration of an ACEinhibitor ameliorated age-related increases in carotid arterial 
stiffness [77]. Nitrates, on the other hand, did not influence aortic stiffness even though they reduced pulse pressure by selective venodilatation and attenuation of peripheral wave reflection [78]. Phosphodiesterase-5 inhibitors like sildenafil work similarly to nitrates and also reduce wave reflection and lower pulse pressure, but without the side effects of nitrates [79]. Arterial stiffness could potentially be improved with HMG-co A enzyme inhibition by statins, although this effect is at least partially attributable to a reduction in LDL cholesterol and NOS activation [80, 81]. However, a recent meta-analysis, which included 471 participants, was unable to demonstrate that statins cause a decrease in arterial stiffness. The authors recommended that prospective randomized clinical trials should be conducted in order to reach more robust conclusions [82].

\section{Conclusions}

Aging leads to a multitude of changes in the cardio-vascular system, and it is a powerful predictor of adverse cardiovascular events. A hallmark of this process is increased central vascular stiffness, which results in an earlier return of the reflected pulse wave, adding to the forward wave and consequently augmenting central systolic blood pressure, widening pulse pressure, increasing cardiac loading conditions, and compromising vital organ perfusion. Although systolic blood pressure and pulse pressure are surrogates for this process, vascular stiffness can be measured more precisely utilizing pulse wave velocity (carotid-femoral) [43].

Vascular stiffness, an index of vascular health, has been shown to confer additional independent predictive value for adverse cardiovascular outcomes. Vascular stiffness is potentially modifiable if we understand the specific underlying mechanisms. Importantly, even in the absence of targeted therapies, an understanding of these concepts has prognostic implications, a concept already established in cardiology and emerging in the area of perioperative medicine.

\section{Funding}

D. E. Berkowitz and D. Nyhan received funding from NIH R01 105296.

\section{Acknowledgments}

The authors wish to thank all members of the ShoukasBerkowitz lab for their support in this project and Mary Ann Anderson for her secretarial assistance.

\section{References}

[1] S. S. Franklin, "Hypertension in older people: part 1," Journal of Clinical Hypertension, vol. 8, no. 6, pp. 444-449, 2006.

[2] M. Watanabe, T. Sawai, H. Nagura, and K. Suyama, "Agerelated alteration of cross-linking amino acids of elastin in human aorta," Tohoku Journal of Experimental Medicine, vol. 180, no. 2, pp. 115-130, 1996.

[3] M. A. Cattell, J. C. Anderson, and P. S. Hasleton, "Age-related changes in amounts and concentrations of collagen and elastin in normotensive human thoracic aorta," Clinica Chimica Acta, vol. 245, no. 1, pp. 73-84, 1996.

[4] D. A. Kass, "Age-related changes in venticular-arterial coupling: pathophysiologic implications," Heart Failure Reviews, vol. 7, no. 1, pp. 51-62, 2002.

[5] G. F. Mitchell, "Effects of central arterial aging on the structure and function of the peripheral vasculature: implications for end-organ damage," Journal of Applied Physiology, vol. 105, no. 5, pp. 1652-1660, 2008.

[6] N. Westerhof, J. W. Lankhaar, and B. E. Westerhof, "The arterial windkessel," Medical and Biological Engineering and Computing, vol. 47, no. 2, pp. 131-141, 2009.

[7] J. C. Greenfield Jr. and D. J. Patel, "Relation between pressure and diameter in the ascending aorta of man," Circulation Research, vol. 10, pp. 778-781, 1962.

[8] A. J. Bank, H. Wang, J. E. Holte, K. Mullen, R. Shammas, and S. H. Kubo, "Contribution of collagen, elastin, and smooth muscle to in vivo human brachial artery wall stress and elastic modulus," Circulation, vol. 94, no. 12, pp. 3263-3270, 1996.

[9] J. L. Izzo Jr., "Arterial stiffness and the systolic hypertension syndrome," Current Opinion in Cardiology, vol. 19, no. 4, pp. 341-352, 2004.

[10] D. H. O’Leary, J. F. Polak, R. A. Kronmal, T. A. Manolio, G. L. Burke, and S. K. Wolfson Jr., "Carotid-artery intima and media thickness as a risk factor for myocardial infarction and stroke in older adults. Cardiovascular Health Study Collaborative Research Group," The New England Journal of Medicine, vol. 340, no. 1, pp. 14-22, 1999.

[11] Y. Nagai, E. J. Metter, C. J. Earley et al., "Increased carotid artery intimal-medial thickness in asymptomatic older subjects with exercise-induced myocardial ischemia," Circulation, vol. 98, no. 15, pp. 1504-1509, 1998.

[12] M. F. O’Rourke and J. Hashimoto, "Mechanical factors in arterial aging: a clinical perspective," Journal of the American College of Cardiology, vol. 50, no. 1, pp. 1-13, 2007.

[13] S. Laurent, A. I. Tropeano, and P. Boutouyrie, "Pulse pressure reduction and cardiovascular protection," Journal of Hypertension-Supplement, vol. 24, no. 3, pp. S13-S18, 2006.

[14] R. D. Semba, S. S. Najjar, K. Sun, E. G. Lakatta, and L. Ferrucci, "Serum carboxymethyl-lysine, an advanced glycation end product, is associated with increased aortic pulse wave velocity in adults," The American Journal of Hypertension, vol. 22, no. 1, pp. 74-79, 2009.

[15] A. J. Bailey, "Molecular mechanisms of ageing in connective tissues," Mechanisms of Ageing and Development, vol. 122, no. 7, pp. 735-755, 2001.

[16] E. Konova, S. Baydanoff, M. Atanasova, and A. Velkova, "Agerelated changes in the glycation of human aortic elastin," Experimental Gerontology, vol. 39, no. 2, pp. 249-254, 2004.

[17] S. J. Zieman, V. Melenovsky, and D. A. Kass, "Mechanisms, pathophysiology, and therapy of arterial stiffness," Arteriosclerosis, Thrombosis and Vascular Biology, vol. 25, no. 5, pp. 932943, 2005.

[18] M. Kuzuya, T. Asai, S. Kanda, K. Maeda, X. W. Cheng, and A. Iguchi, "Glycation cross-links inhibit matrix metalloproteinase-2 activation in vascular smooth muscle cells cultured on collagen lattice," Diabetologia, vol. 44, no. 4, pp. 433-436, 2001.

[19] T. Wendt, L. Bucciarelli, W. Qu et al., "Receptor for advanced glycation endproducts (RAGE) and vascular inflammation: insights into the pathogenesis of macrovascular complications in diabetes," Current Atherosclerosis Reports, vol. 4, no. 3, pp. 228-237, 2002. 
[20] D. M. Stern, S. D. Yan, S. F. Yan, and A. M. Schmidt, "Receptor for advanced glycation endproducts (RAGE) and the complications of diabetes," Ageing Research Reviews, vol. 1, no. 1, pp. $1-15,2002$.

[21] D. Stern, S. D. Yan, S. F. Yan, and A. M. Schmidt, "Receptor for advanced glycation endproducts: a multiligand receptor magnifying cell stress in diverse pathologic settings," Advanced Drug Delivery Reviews, vol. 54, no. 12, pp. 1615-1625, 2002.

[22] D. A. Kass, E. P. Shapiro, M. Kawaguchi et al., "Improved arterial compliance by a novel advanced glycation endproduct crosslink breaker," Circulation, vol. 104, no. 13, pp. 1464-1470, 2001.

[23] J. J. Oliver and D. J. Webb, "Noninvasive assessment of arterial stiffness and risk of atherosclerotic events," Arteriosclerosis, Thrombosis and Vascular Biology, vol. 23, no. 4, pp. 554-566, 2003.

[24] G. H. Gurtner and T. Burke-Wolin, "Interactions of oxidant stress and vascular reactivity," The American Journal of Physiology, vol. 260, no. 4, pp. L207-L211, 1991.

[25] M. Yanagisawa, H. Kurihara, S. Kimura, K. Goto, and T. Masaki, "A novel peptide vasoconstrictor, endothelin, is produced by vascular endothelium and modulates smooth muscle Ca2+ channels," Journal of Hypertension-Supplement, vol. 6, no. 4, pp. S188-S191, 1988.

[26] V. J. Dzau, "Significance of the vascular renin-angiotensin pathway," Hypertension, vol. 8, no. 7, pp. 553-559, 1986.

[27] T. M. Griffith, D. H. Edwards, M. J. Lewis, A. C. Newby, and A. H. Henderson, "The nature of endothelium-derived vascular relaxant factor," Nature, vol. 308, no. 5960, pp. 645-647, 1984.

[28] W. K. Alderton, C. E. Cooper, and R. G. Knowles, "Nitric oxide synthases: structure, function and inhibition," Biochemical Journal, vol. 357, no. 3, pp. 593-615, 2001.

[29] S. V. Raju, L. A. Barouch, and J. M. Hare, "Nitric oxide and oxidative stress in cardiovascular aging," Science of Aging Knowledge Environment, vol. 2005, no. 21, p. re4, 2005.

[30] L. Santhanam, H. K. Lim, H. K. Lim et al., "Inducible NO synthase-dependent S-nitrosylation and activation of arginase1 contribute to age-related endothelial dysfunction," Circulation Research, vol. 101, no. 7, pp. 692-702, 2007.

[31] S. J. Zieman, G. Gerstenblith, E. G. Lakatta et al., "Upregulation of the nitric oxide-cGMP pathway in aged myocardium: physiological response to L-arginine," Circulation Research, vol. 88, no. 1, pp. 97-102, 2001.

[32] H. Li and U. Förstermann, "Prevention of atherosclerosis by interference with the vascular nitric oxide system," Current Pharmaceutical Design, vol. 15, no. 27, pp. 3133-3145, 2009.

[33] R. A. Dulce, I. H. Schulman, and J. M. Hare, "S-glutathionylation: a redox-sensitive switch participating in nitroso-redox balance," Circulation Research, vol. 108, no. 5, pp. 531-533, 2011.

[34] C. A. Chen, T. Y. Wang, S. Varadharaj et al., "S-glutathionylation uncouples eNOS and regulates its cellular and vascular function," Nature, vol. 468, no. 7327, pp. 1115-1118, 2010.

[35] J. Steppan, S. Ryoo, K. H. Schuleri et al., "Arginase modulates myocardial contractility by a nitric oxide synthase 1dependent mechanism," Proceedings of the National Academy of Sciences of the United States of America, vol. 103, no. 12, pp. 4759-4764, 2006.

[36] L. Santhanam, E. C. Tuday, A. K. Webb et al., "Decreased Snitrosylation of tissue transglutaminase contributes to agerelated increases in vascular stiffness," Circulation Research, vol. 107, no. 1, pp. 117-125, 2010.
[37] N. Chabot, S. Moreau, A. Mulani, P. Moreau, and J. W. Keillor, "Fluorescent probes of tissue transglutaminase reveal its association with arterial stiffening," Chemistry and Biology, vol. 17, no. 10, pp. 1143-1150, 2010.

[38] P. d'Alessio, “Aging and the endothelium," Experimental Gerontology, vol. 39, no. 2, pp. 165-171, 2004.

[39] K. Tziomalos and J. M. Hare, "Role of xanthine oxidoreductase in cardiac nitroso-redox imbalance," Frontiers in Bioscience, vol. 14, pp. 237-262, 2009.

[40] R. L. Matz, C. Schott, J. C. Stoclet, and R. Andriantsitohaina, "Age-related endothelial dysfunction with respect to nitric oxide, endothelium-derived hyperpolarizing factor and cyclooxygenase products," Physiological Research, vol. 49, no. 1, pp. 11-18, 2000.

[41] S. Taddei, A. Virdis, L. Ghiadoni et al., "Age-related reduction of NO availability and oxidative stress in humans," Hypertension, vol. 38, no. 2, pp. 274-279, 2001.

[42] X. Peng, S. Haldar, S. Deshpande, K. Irani, and D. A. Kass, "Wall stiffness suppresses Akt/eNOS and cytoprotection in pulse-perfused endothelium," Hypertension, vol. 41, no. 2, pp. 378-381, 2003.

[43] S. Laurent and P. Boutouyrie, "Arterial stiffness: a new surrogate end point for cardiovascular disease?" Journal of Nephrology, vol. 20, supplement 12, pp. S45-S50, 2007.

[44] A. P. Avolio, L. M. Van Bortel, P. Boutouyrie et al., "Role of pulse pressure amplification in arterial hypertension: experts' opinion and review of the data," Hypertension, vol. 54 , no. 2 , pp. 375-383, 2009.

[45] G. F. Mitchell, N. Wang, J. N. Palmisano et al., "Hemodynamic correlates of blood pressure across the adult age spectrum: noninvasive evaluation in the Framingham Heart Study," Circulation, vol. 122, no. 14, pp. 1379-1386, 2010.

[46] C. Vlachopoulos, K. Aznaouridis, and C. Stefanadis, "Prediction of cardiovascular events and all-cause mortality with arterial stiffness: a systematic review and meta-analysis," Journal of the American College of Cardiology, vol. 55, no. 13, pp. 1318-1327, 2010.

[47] G. F. Mitchell, J. L. Izzo Jr., Y. Lacourcière et al., “Omapatrilat reduces pulse pressure and proximal aortic stiffness in patients with systolic hypertension: results of the conduit hemodynamics of omapatrilat international research study," Circulation, vol. 105, no. 25, pp. 2955-2961, 2002.

[48] S. Laurent, P. Boutouyrie, R. Asmar et al., "Aortic stiffness is an independent predictor of all-cause and cardiovascular mortality in hypertensive patients," Hypertension, vol. 37, no. 5, pp. 1236-1241, 2001.

[49] G. F. Mitchell, S. J. Hwang, R. S. Vasan et al., "Arterial stiffness and cardiovascular events: the Framingham Heart Study," Circulation, vol. 121, no. 4, pp. 505-511, 2010.

[50] S. Madhavan, W. L. Ooi, H. Cohen, and M. H. Alderman, "Relation of pulse pressure and blood pressure reduction to the incidence of myocardial infarction," Hypertension, vol. 23, no. 3, pp. 395-401, 1994.

[51] S. S. Franklin, W. Gustin, N. D. Wong et al., "Hemodynamic patterns of age-related changes in blood pressure. The Framingham Heart Study," Circulation, vol. 96, no. 1, pp. 308-315, 1997.

[52] A. Benetos, A. Rudnichi, M. Safar, and L. Guize, "Pulse pressure and cardiovascular mortality in normotensive and hypertensive subjects," Hypertension, vol. 32, no. 3, pp. 560564, 1998.

[53] S. S. Franklin, S. A. Khan, N. D. Wong, M. G. Larson, and D. Levy, "Is pulse pressure useful in predicting risk for coronary 
heart disease? The Framingham Heart Study," Circulation, vol. 100, no. 4, pp. 354-360, 1999.

[54] B. Darne, X. Girerd, M. Safar, F. Cambien, and L. Guize, "Pulsatile versus steady component of blood pressure: a crosssectional analysis and a prospective analysis on cardiovascular mortality," Hypertension, vol. 13, no. 4, pp. 392-400, 1989.

[55] K. Sutton-Tyrrell, S. S. Najjar, R. M. Boudreau et al., "Elevated aortic pulse wave velocity, a marker of arterial stiffness, predicts cardiovascular events in well-functioning older adults," Circulation, vol. 111, no. 25, pp. 3384-3390, 2005.

[56] F. U. Mattace-Raso, T. J. van der Cammen, A. Hofman et al., "Arterial stiffness and risk of coronary heart disease and stroke: the Rotterdam Study," Circulation, vol. 113, no. 5, pp. 657-663, 2006.

[57] T. Willum-Hansen, J. A. Staessen, C. Torp-Pedersen et al., "Prognostic value of aortic pulse wave velocity as index of arterial stiffness in the general population," Circulation, vol. 113, no. 5, pp. 664-670, 2006.

[58] M. J. Roman, R. B. Devereux, J. R. Kizer et al., "Central pressure more strongly relates to vascular disease and outcome than does brachial pressure: the Strong Heart Study," Hypertension, vol. 50, no. 1, pp. 197-203, 2007.

[59] C. Manisty, J. Mayet, R. J. Tapp et al., "Wave reflection predicts cardiovascular events in hypertensive individuals independent of blood pressure and other cardiovascular risk factors: an ASCOT (Anglo-Scandinavian Cardiac Outcome Trial) substudy," Journal of the American College of Cardiology, vol. 56, no. 1, pp. 24-30, 2010.

[60] M. E. Safar, J. Blacher, B. Pannier et al., "Central pulse pressure and mortality in end-stage renal disease," Hypertension, vol. 39, no. 3, pp. 735-738, 2002.

[61] E. Dolan, L. Thijs, Y. Li et al., "Ambulatory arterial stiffness index as a predictor of cardiovascular mortality in the Dublin Outcome Study," Hypertension, vol. 47, no. 3, pp. 365-370, 2006.

[62] A. Benetos, F. Thomas, L. Joly et al., "Pulse pressure amplification a mechanical biomarker of cardiovascular risk," Journal of the American College of Cardiology, vol. 55, no. 10, pp. 10321037, 2010.

[63] S. Aronson, M. L. Fontes, Y. Miao, and D. T. Mangano, "Risk index for perioperative renal dysfunction/failure: critical dependence on pulse pressure hypertension," Circulation, vol. 115, no. 6, pp. 733-742, 2007.

[64] A. Benjo, R. E. Thompson, D. Fine et al., "Pulse pressure is an age-independent predictor of stroke development after cardiac surgery," Hypertension, vol. 50, no. 4, pp. 630-635, 2007.

[65] N. M. Nikolov, M. L. Fontes, W. D. White et al., "Pulse pressure and long-term survival after coronary artery bypass graft surgery," Anesthesia and Analgesia, vol. 110, no. 2, pp. 335-340, 2010.

[66] "Determinants of pulse wave velocity in healthy people and in the presence of cardiovascular risk factors: 'establishing normal and reference values', The European Heart Journal, vol. 31, no. 19, pp. 2338-2350, 2010.

[67] B. Williams, P. S. Lacy, S. M. Thom et al., "Differential impact of blood pressure-lowering drugs on central aortic pressure and clinical outcomes: principal results of the Conduit Artery Function Evaluation (CAFE) study," Circulation, vol. 113, no. 9, pp. 1213-1225, 2006.

[68] R. J. Doonan, A. Hausvater, C. Scallan, D. P. Mikhailidis, L. Pilote, and S. S. Daskalopoulou, "The effect of smoking on arterial stiffness," Hypertension Research, vol. 33, no. 5, pp. 398-410, 2010.
[69] P. Nestel, H. Shige, S. Pomeroy, M. Cehun, M. Abbey, and D. Raederstorff, "The n-3 fatty acids eicosapentaenoic acid and docosahexaenoic acid increase systemic arterial compliance in humans," The American Journal of Clinical Nutrition, vol. 76, no. 2, pp. 326-330, 2002.

[70] Y. T. van der Schouw, A. Pijpe, C. E. Lebrun et al., "Higher usual dietary intake of phytoestrogens is associated with lower aortic stiffness in postmenopausal women," Arteriosclerosis, Thrombosis and Vascular Biology, vol. 22, no. 8, pp. 1316-1322, 2002.

[71] F. M. Sacks, L. P. Svetkey, W. M. Vollmer et al., "Effects on blood pressure of reduced dietary sodium and the Dietary Approaches to Stop Hypertension (DASH) diet. DASHSodium Collaborative Research Group," The New England Journal of Medicine, vol. 344, no. 1, pp. 3-10, 2001.

[72] J. D. Cameron and A. M. Dart, "Exercise training increases total systemic arterial compliance in humans," The American Journal of Physiology, vol. 266, no. 2, pp. H693-H701, 1994.

[73] A. Sierksma, C. E. Lebrun, Y. T. van der Schouw et al., "Alcohol consumption in relation to aortic stiffness and aortic wave reflections: a cross-sectional study in healthy postmenopausal women," Arteriosclerosis, Thrombosis and Vascular Biology, vol. 24, no. 2, pp. 342-348, 2004.

[74] A. Sierksma, M. Muller, Y. T. van der Schouw, D. E. Grobbee, H. F. Hendriks, and M. L. Bots, "Alcohol consumption and arterial stiffness in men," Journal of Hypertension, vol. 22, no. 2, pp. 357-362, 2004.

[75] N. de Luca, R. G. Asmar, G. M. London, M. F. O’Rourke, and M. E. Safar, "Selective reduction of cardiac mass and central blood pressure on low-dose combination perindopril/indapamide in hypertensive subjects," Journal of Hypertension, vol. 22, no. 8, pp. 1623-1630, 2004.

[76] T. Morgan, J. Lauri, D. Bertram, and A. Anderson, "Effect of different antihypertensive drug classes on central aortic pressure," The American Journal of Hypertension, vol. 17, no. 2, pp. 118-123, 2004.

[77] K. Hayashi, K. Miyagawa, K. Sato, R. Ueda, and Y. Dohi, "Temocapril, an angiotensin converting enzyme inhibitor, ameliorates age-related increase in carotid arterial stiffness in normotensive subjects," Cardiology, vol. 106, no. 3, pp. 190194, 2006.

[78] D. H. Fitchett, G. J. Simkus, J. P. Beaudry, and D. G. F. Marpole, "Reflected pressure waves in the ascending aorta: effect of glyceryl trinitrate," Cardiovascular Research, vol. 22, no. 7, pp. 494-500, 1988.

[79] C. Vlachopoulos, K. Hirata, and M. F. O'Rourke, "Effect of sildenafil on arterial stiffness and wave reflection," Vascular Medicine, vol. 8, no. 4, pp. 243-248, 2003.

[80] T. J. Smilde, F. W. van den Berkmortel, H. Wollersheim, H. van Langen, J. J. Kastelein, and A. F. Stalenhoef, "The effect of cholesterol lowering on carotid and femoral artery wall stiffness and thickness in patients with familial hypercholesterolaemia," The European Journal of Clinical Investigation, vol. 30, no. 6, pp. 473-480, 2000.

[81] M. Takemoto and J. K. Liao, "Pleiotropic effects of 3hydroxy-3-methylglutaryl coenzyme a reductase inhibitors," Arteriosclerosis, Thrombosis and Vascular Biology, vol. 21, no. 11, pp. 1712-1719, 2001.

[82] E. C. Rizos, A. P. Agouridis, and M. S. Elisaf, "The effect of statin therapy on arterial stiffness by measuring pulse wave velocity: a systematic review," Current Vascular Pharmacology, vol. 8, pp. 638-644, 2010. 


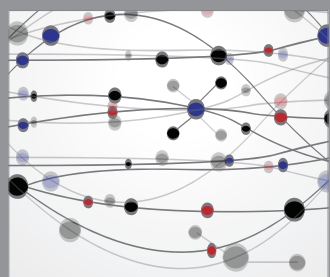

The Scientific World Journal
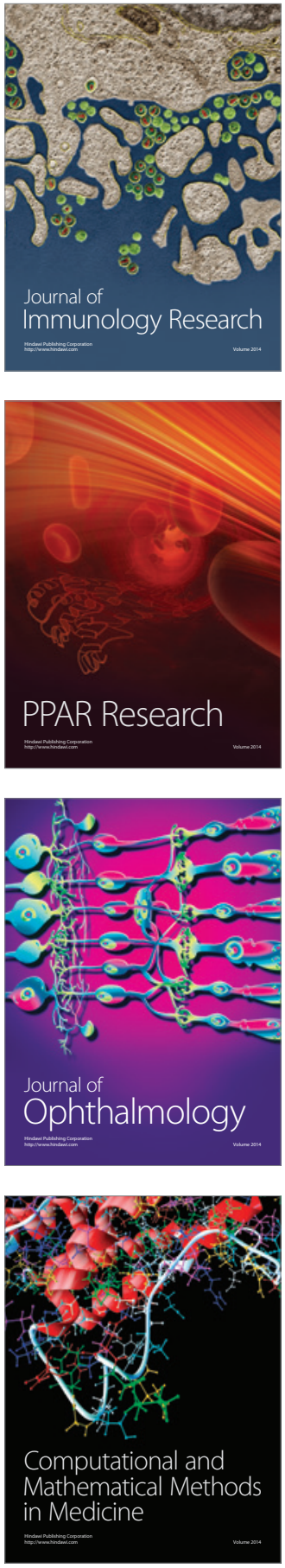

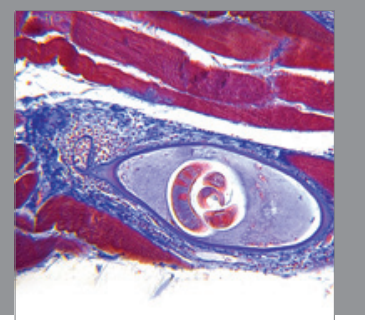

Gastroenterology

Research and Practice
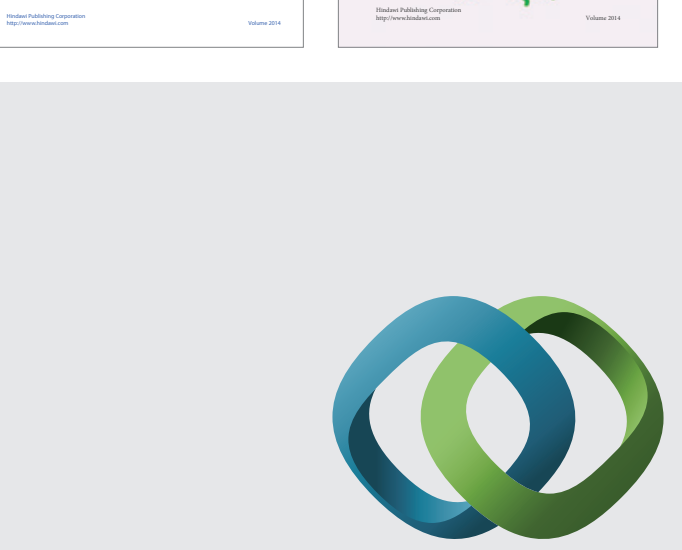

\section{Hindawi}

Submit your manuscripts at

http://www.hindawi.com
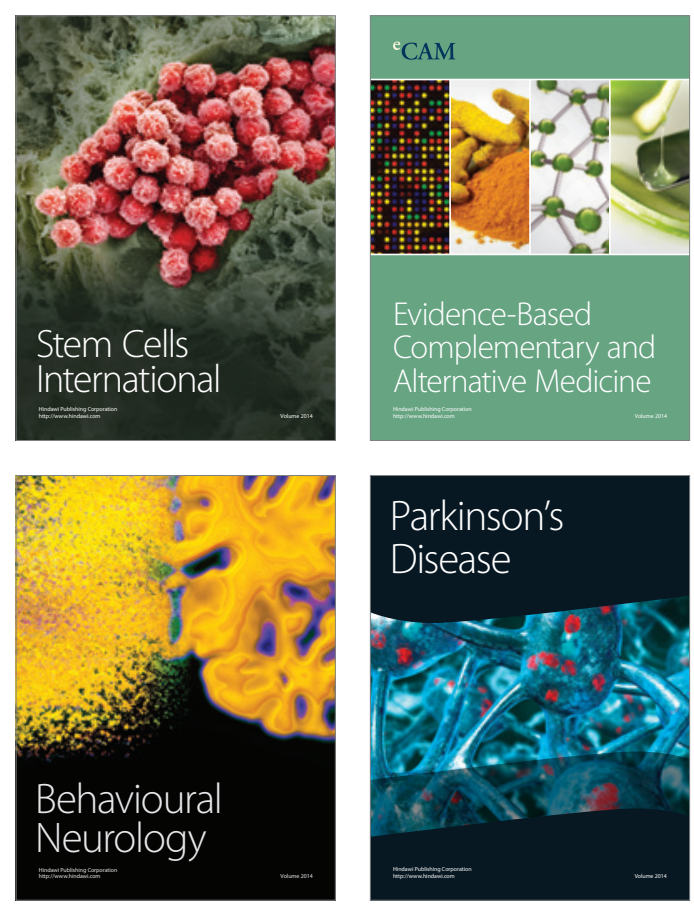

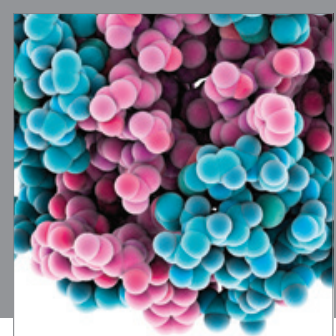

Journal of
Diabetes Research

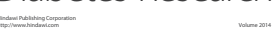

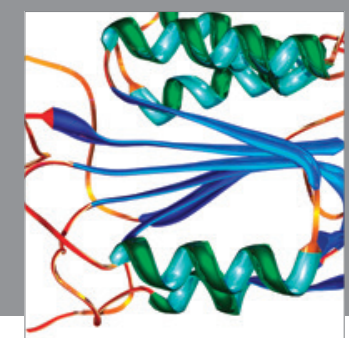

Disease Markers
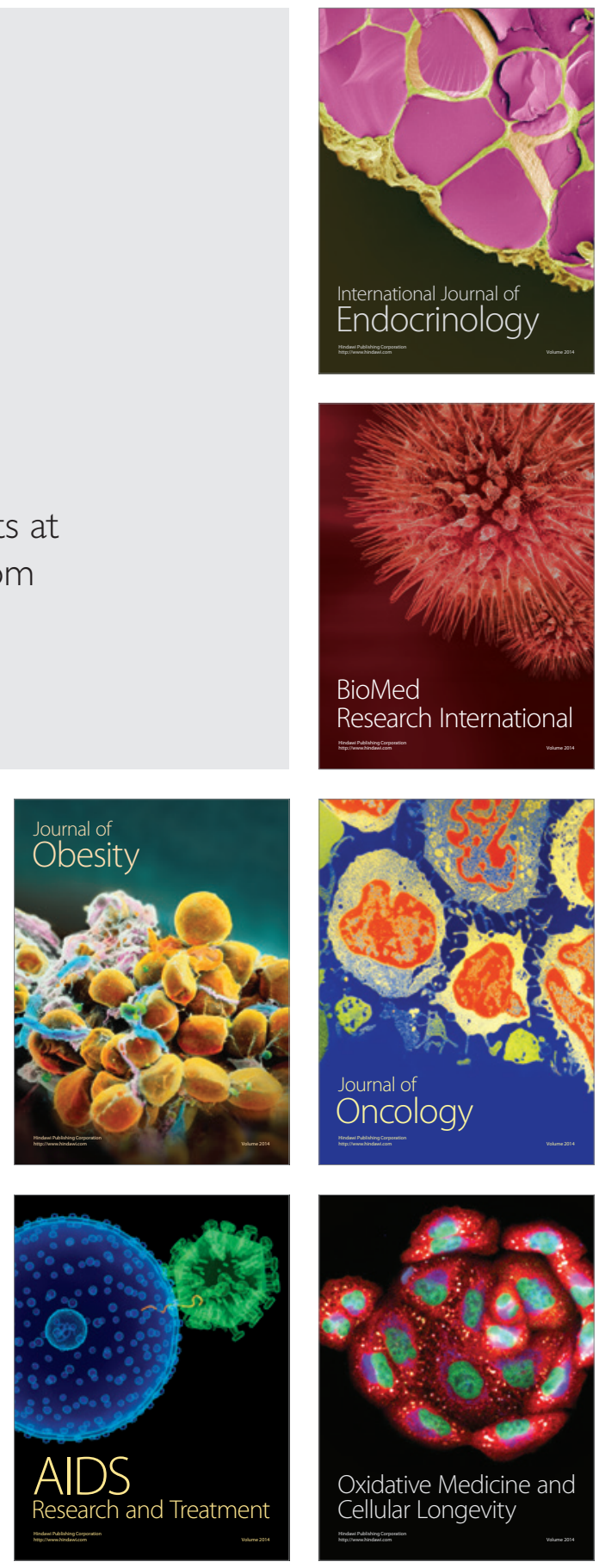